\title{
Fault Tolerant Control of DC-Link Voltage Sensor for Three-Phase AC/DC/AC PWM Converters
}

\author{
Soo-Cheol Kim*, Thanh Hai Nguyen ${ }^{* *}$, Dong-Choon Lee ${ }^{\dagger}$, Kyo-Beum Lee ${ }^{* * *}$, and Jang-Mok Kim ${ }^{* * * *}$ \\ *Daewoo Shipbuilding and Marine Engineering Co., Ltd., Seoul, Korea \\ ${ }^{* * *}$ Department of Electrical Engineering, Yeungnam University, Gyeongsan, Korea \\ ${ }^{* * *}$ Department of Electrical and Computer Engineering, Ajou University, Suwon, Korea \\ Department of Electrical Engineering, Pusan National University, Pusan, Korea
}

\begin{abstract}
In this paper, a fault detection scheme for DC-link voltage sensor and its fault tolerant control strategy for three-phase AC/DC/AC PWM converters are proposed, where the Luenberger observer is applied to estimate the DC-link voltage. The Luenberger observer is based on a converter model, which is derived from the voltage equations of a grid-side converter and the power balance on a DC link. A fault of the voltage sensor is detected by comparing the measured value of the DC-link voltage with the estimated one. When a sensor fault is detected, a fault tolerant control strategy is performed, where the estimated DC-link voltage is used for the feedback control. The estimation error from the observer is about $1.5 \mathrm{~V}$, which is sufficiently accurate for feedback control. In addition, it is shown that the observer performance is robust to parameter variations of the converter. The validity of the proposed method has been verified by simulation and experimental results.
\end{abstract}

Key words: DC-link voltage, Estimation, Fault tolerant control, Luenberger observer, PWM converter

\section{INTRODUCTION}

$\mathrm{AC} / \mathrm{DC} / \mathrm{AC} \mathrm{PWM}$ converters are widely used in various industrial areas such as electric machine drives, UPSs (uninterruptible power supply), UPQCs (unified power quality conditioner) and grid-connected renewable energy systems [1][3]. A research survey has reported that the failure rates of these converter are $30 \%, 26 \%, 21 \%$ and $13 \%$ due to their capacitors, printed circuit boards, semiconductors, and soldering, respectively [4], [5]. Therefore, the reliability and performance of PWM converters has been paid a great deal of attention. Recently, fault detection and tolerant control techniques for power converters have attracted a lot of interest due to their higher reliability and lower maintenance.

Therefore, some studies on the fault detection and tolerant control of the PWM converters, which are mainly on the openor short-circuits of switching devices and DC-link capacitors, have been introduced [6]-[12]. However, the fault detection of

Manuscript received Jan. 15, 2014; accepted Apr. 17, 2014 Recommended for publication by Associate Editor Se-Kyo Chung. †Corresponding Author: dclee@yu.ac.kr

Tel: +82-53-810-2582, Fax: +82-53-810-4767, Yeungnam Univ.

"Daewoo Shipbuilding and Marine Engineering Co., Ltd., Korea

*** Dept. of Electrical Eng., Yeungnam University, Korea

${ }_{* * * *}^{* *}$ Dept. of Electrical and Computer Eng., Ajou University, Korea

*****Dept. of Electrical Eng., Pusan National University, Korea the sensor and its tolerant control scheme have not been studied very much. A study on DC-link voltage sensorless control has been reported [13], which focuses on cost reduction rather than preparation for failures. Therefore, research on the fault diagnosis and tolerant control of DC voltage sensor is needed.

The control of a PWM-VSC (voltage-source converter) requires information on the DC-link voltage, and the grid voltages and currents, where the control performance depends a great deal on accurate measurements by voltage and current sensors. In the case of a malfunction of a DC voltage sensor, the DC-link voltage cannot be controlled at a desired value, which may damage or trip the system. In addition, if the measured value of the DC-link voltage contains a ripple component, the input current of the PWM converter is also distorted by the action of the DC-link voltage controller [14].

Recently, several studies have been presented to estimate DC-link voltage. At first, DC-link voltage monitoring was studied for grid-connected wind turbine converters [14], where a combination of the PI (proportional-integral) control and the predictive algorithm is employed to compensate for measurement errors of the DC-link voltage. This method requires a high sampling frequency (equal to four times the switching frequency) with a complicated timing synchronization for the sampling and prediction of currents and voltages. Another method has been introduced, which 


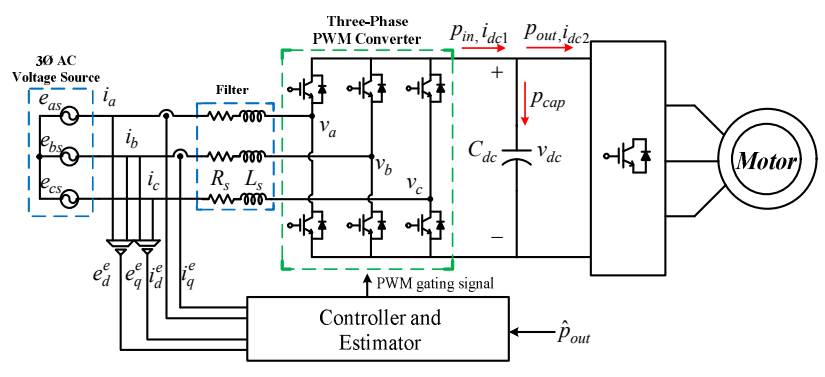

Fig. 1. Three-phase AC/DC/AC PWM converter.

estimates the DC-link and source voltages simultaneously using a switching table and a derivative of the boost inductor current [15]. In this scheme, the estimation performance is sensitive to measurement noise. Furthermore, if the switching time is not chosen appropriately for the initial estimation at start-up, the wrong estimation may cause an overcurrent. In another method, the DC-link voltage and grid currents are estimated by a sliding mode observer [16]. A disadvantage of this method is that an undesirable chattering phenomenon is inevitable on the estimation variables. In addition, experimental verification of the actual system has not been provided.

In this paper, fault detection for the DC-link voltage sensor and its tolerant control scheme are proposed for three-phase AC/DC/AC PWM converters, where the Luenberger observer is employed to estimate the DC-link voltage. For this estimation scheme, the PWM converter is modeled as a nonlinear system which results from including the power balance between the input and the output. At first, the nonlinearity of the PWM converter model is linearized by using a small signal analysis [17]-[19]. Then, the Luenberger observer is applied to estimate the DC-link voltage, since it is known to give good performance with a fast responses and high reliability. The estimation error is less than $3 \%$ in the transient states of the load change or variations of the system parameters. The fault condition of the DC voltage sensor is discerned by comparing the measured value with the estimated one. Then, the DC-link voltage is still controlled well during the sensor fault by feeding the estimated one back. The validity of the proposed estimation and control method is verified by simulation and experimental results.

\section{NONLINEAR MODELING OF AC/DC PWM CONVERTERS}

Fig. 1 shows the three-phase AC/DC/AC PWM converters for the AC motor drives.

\section{A. Voltage Equations}

The voltage equations in a three-phase AC/DC PWM converter are expressed as:

$$
e_{a}=R_{s} i_{a}+L_{s} \frac{d i_{a}}{d t}+v_{a}
$$

$$
\begin{aligned}
& e_{b}=R_{s} i_{b}+L_{s} \frac{d i_{b}}{d t}+v_{b} \\
& e_{c}=R_{s} i_{c}+L_{s} \frac{d i_{c}}{d t}+v_{c}
\end{aligned}
$$

where $e_{a}, e_{b}$ and $e_{c}$ are the input phase voltages, $i_{a}, i_{b}$ and $i_{c}$ are the input currents, and $v_{a}, v_{b}$ and $v_{c}$ are the input voltages of the converter. In addition, $R_{s}$ and $L_{s}$ are the resistances and inductances in the AC side, respectively.

The source voltage can be rewritten in the $d-q$ synchronous reference frame as [1]:

$$
\begin{aligned}
& e_{d}^{e}=R_{s} i_{d}^{e}+L_{s} p i_{d}^{e}-L_{s} \omega_{e} i_{q}^{e}+v_{d}^{e} \\
& e_{q}^{e}=R_{s} i_{q}^{e}+L_{s} p i_{q}^{e}+L_{s} \omega_{e} i_{d}^{e}+v_{q}^{e}
\end{aligned}
$$

where the superscript ' $e$ ' represents a quantity in the synchronous reference frame and ' $p$ ' denotes a differential operator.

In (4) and (5), the converter input voltages, $v_{d q}^{e}$, can be expressed as:

$$
\begin{gathered}
v_{d}^{e}=d_{d}^{e} v_{d c} \\
v_{q}^{e}=d_{q}^{e} v_{d c}
\end{gathered}
$$

where $v_{d c}$ is the DC-link voltage, and $v_{d}^{e}$ and $v_{q}^{e}$ are the duty ratios transformed into the $\mathrm{d}-\mathrm{q}$ frame from the $\mathrm{a}-\mathrm{b}-\mathrm{c}$ frame [17], [18].

\section{B. Power Balance in the DC-Link}

The power flow at the DC-link side of the back-to-back converter is shown in Fig. 1, and is expressed as:

$$
p_{\text {cap }}=p_{\text {in }}-p_{\text {out }}
$$

where $p_{\text {cap }}$ is the capacitor power, $p_{\text {in }}$ is the input power flowing into the DC-link from the AC source with the converter loss neglected, and $p_{\text {out }}$ is the output power delivered from the DClink to the load. The input power can be expressed with the source voltage and current in the synchronous reference frame as:

$$
p_{\text {in }}=e_{a} i_{a}+e_{b} i_{b}+e_{c} i_{c}=\frac{3}{2}\left(e_{d}^{e} i_{d}^{e}+e_{q}^{e} i_{q}^{e}\right)
$$

The output power is given by:

$$
p_{\text {out }}=v_{d c} i_{d c 2}
$$

where $i_{d c 2}$ is the output current of the DC-link side.

The capacitor power is expressed as [1]:

$$
p_{c a p}=\frac{1}{2} C_{d c} \frac{d v_{d c}^{2}}{d t} \approx V_{d c 0} C_{d c} \frac{d v_{d c}}{d t}
$$

where $C_{d c}$ is the DC-link capacitance, and $V_{d c}$ is the DC-link voltage at the operating point. In order to keep the DC-link voltage constant, the variation of the capacitor power is required to be zero. 


\section{Nonlinear Modeling of the AC/DC PWM Converter}

By rearranging equations (4) to (11), the nonlinear model of the three-phase AC/DC PWM converter is described as [20]:

$$
\begin{aligned}
& \dot{x}=f(x)+g \cdot u \\
& y=h(x)
\end{aligned}
$$

where:

$$
\begin{aligned}
& f(x)=\left[\begin{array}{c}
-\frac{R_{s}}{L_{s}} i_{d}^{e}+\omega_{e} i_{q}^{e}-\frac{1}{L_{s}} d_{d}^{e} v_{d c} \\
-\omega_{e} i_{d}^{e}-\frac{R_{s}}{L_{s}}-\frac{1}{L_{s}} d_{q}^{e} v_{d c} \\
1.5\left(\frac{e_{d}^{e} i_{d}^{e}}{C_{d c} v_{d c}}+\frac{e_{q}^{e} i_{q}^{e}}{C_{d c} v_{d c}}\right)
\end{array}\right], g \cdot u=\left[\begin{array}{c}
\frac{e_{d}^{e}}{L_{s}} \\
\frac{e_{q}^{e}}{L_{s}} \\
-\frac{P_{o u t}}{C_{d c} v_{d c}}
\end{array}\right], \\
& h(x)=\left[\begin{array}{ll}
i_{d}^{e} & i_{q}^{e}
\end{array}\right] .
\end{aligned}
$$

III. ESTIMATION OF DC-LINK VOLTAGE BY THE LUENBERGER OBSERVER

\section{A. Luenberger Observer}

The Luenberger observer is a kind of state observer which estimates the internal state of linear systems. The state equations for the Luenberger observer are expressed as [20][24]:

$$
\begin{aligned}
& \dot{\hat{\mathbf{x}}}(t)=\mathbf{A} \hat{\mathbf{x}}(t)+\mathbf{B u}(t)+\mathbf{L}(\mathbf{y}(t)-\hat{\mathbf{y}}(t)) \\
& \hat{\mathbf{y}}(t)=C \hat{\mathbf{x}}(t)
\end{aligned}
$$

where "^" indicates the estimated values, $\mathrm{x}(\mathrm{t})$ is the state vector, $\mathrm{u}(\mathrm{t})$ is the input vector, $\mathrm{y}(\mathrm{t})$ is the output vector, $\mathbf{A}, \mathbf{B}$ and $\mathbf{C}$ are the system parameter matrices, and $\mathbf{L}$ is the observer gain matrix. The observer error dynamic is expressed as:

$$
\dot{\tilde{\mathbf{x}}}(t)=(\mathbf{A}-\mathbf{L C}) \tilde{\mathbf{x}}(t)
$$

where: $\tilde{\mathbf{x}}(t)=\mathbf{x}(t)-\hat{\mathbf{x}}(t)$.

Fig. 2 shows a block diagram of the Luenberger observer. In order to ensure that the estimation error approaches zero asymptotically from any of the initial states, the observer poles should be placed on the left-half plane, which is set by the gain matrix $\mathbf{L}$. In this study, the observer poles are placed in order to have one real and two complex roots, as $p$ and $\alpha \pm j \beta$, respectively [25].

B. Linearization of the Nonlinear System of an $A C / D C$ PWM Converter

First, the nonlinear system in (12) is linearized by smallsignal analysis. Then, the linear system is obtained as [18], [19]:

$$
\begin{aligned}
& \dot{\mathbf{x}}(t)=\mathbf{A x}(t)+\mathbf{B u}(t) \\
& \mathbf{y}(t)=\mathbf{C} \mathbf{x}(t)
\end{aligned}
$$

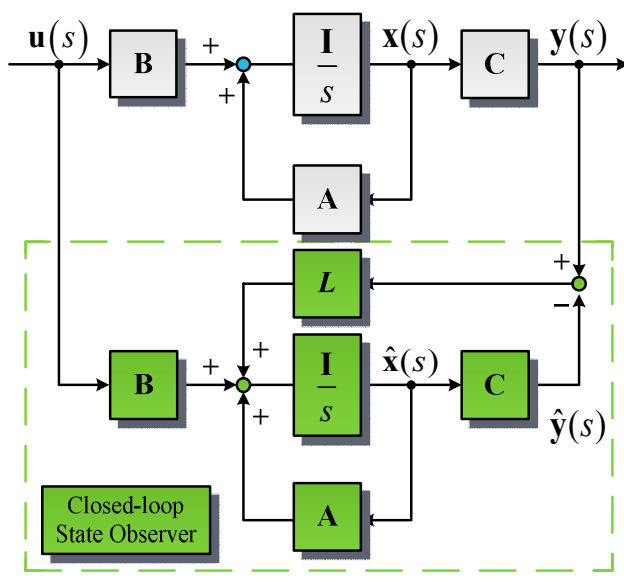

Fig. 2. Block diagram of Luenberger observer.

$$
\begin{aligned}
& \mathbf{x}(t)=\left[\begin{array}{lll}
i_{d}^{e} & i_{q}^{e} & v_{d c}
\end{array}\right]^{T}, \mathbf{u}(t)=\left[\begin{array}{lllll}
e_{d}^{e} & e_{q}^{e} & d_{d}^{e} & d_{q}^{e} & P_{\text {out }}
\end{array}\right]^{T}, \\
& \mathbf{y}(t)=\left[\begin{array}{ll}
i_{d}^{e} & i_{q}^{e}
\end{array}\right]^{T}
\end{aligned}
$$

$$
\mathbf{A}=\left[\begin{array}{ccc}
-\frac{R_{s}}{L_{s}} & \omega_{e} & -\frac{D_{d o}^{e}}{L_{s}} \\
\omega_{e} & -\frac{R_{s}}{L_{s}} & -\frac{D_{q o}^{e}}{L_{s}} \\
\frac{1.5 E_{d o}^{e}}{C_{d c} V_{d c o}} & \frac{1.5 E_{q o}^{e}}{C_{d c} V_{d c o}} & 0
\end{array}\right], \mathbf{C}=\left[\begin{array}{ccc}
1 & 0 & 0 \\
0 & 1 & 0
\end{array}\right]
$$

$$
\mathbf{B}=\left[\begin{array}{ccccc}
\frac{1}{L_{s}} & 0 & -\frac{V_{d c o}}{L_{s}} & 0 & 0 \\
0 & \frac{1}{L_{s}} & 0 & -\frac{V_{d c o}}{L_{s}} & 0 \\
\frac{1.5 I_{d o}^{e}}{C_{d c} V_{d c o}} & \frac{1.5 I_{q o}^{e}}{C_{d c} V_{d c o}} & 0 & 0 & -\frac{1}{C_{d c} V_{d c o}}
\end{array}\right]
$$

In (15) and (16), the upper-case variables $\left(I_{d 0}^{e}, I_{q 0}^{e}, E_{d 0}^{e}, E_{q 0}^{e}, D_{d 0}^{e}, D_{q 0}^{e}, V_{d c 0}\right)$ refer to the operating points in the steady state, whereas the lower-case variables $\left(i_{d}^{e}, i_{q}^{e}, e_{d}^{e}, e_{q}^{e}, d_{d}^{e}, d_{q}^{e}, v_{d c}\right)$ represent the perturbations around their operating points.

\section{Determination of the Luenberger Observer Gains}

In order to obtain stable estimation for all of the ranges of the DC-link voltage and the variations of the system parameters $\left(L_{s}\right.$, $C_{d c}$ ), the observer gain matrix should be selected so that the real parts of all eigenvalues of (A-LC) are negative. In this case the observer gain matrix $\mathbf{L}$ is expressed as:

$$
\mathbf{L}=\left[\begin{array}{ll}
L_{11} & L_{12} \\
L_{21} & L_{22} \\
L_{31} & L_{32}
\end{array}\right] .
$$

where: 


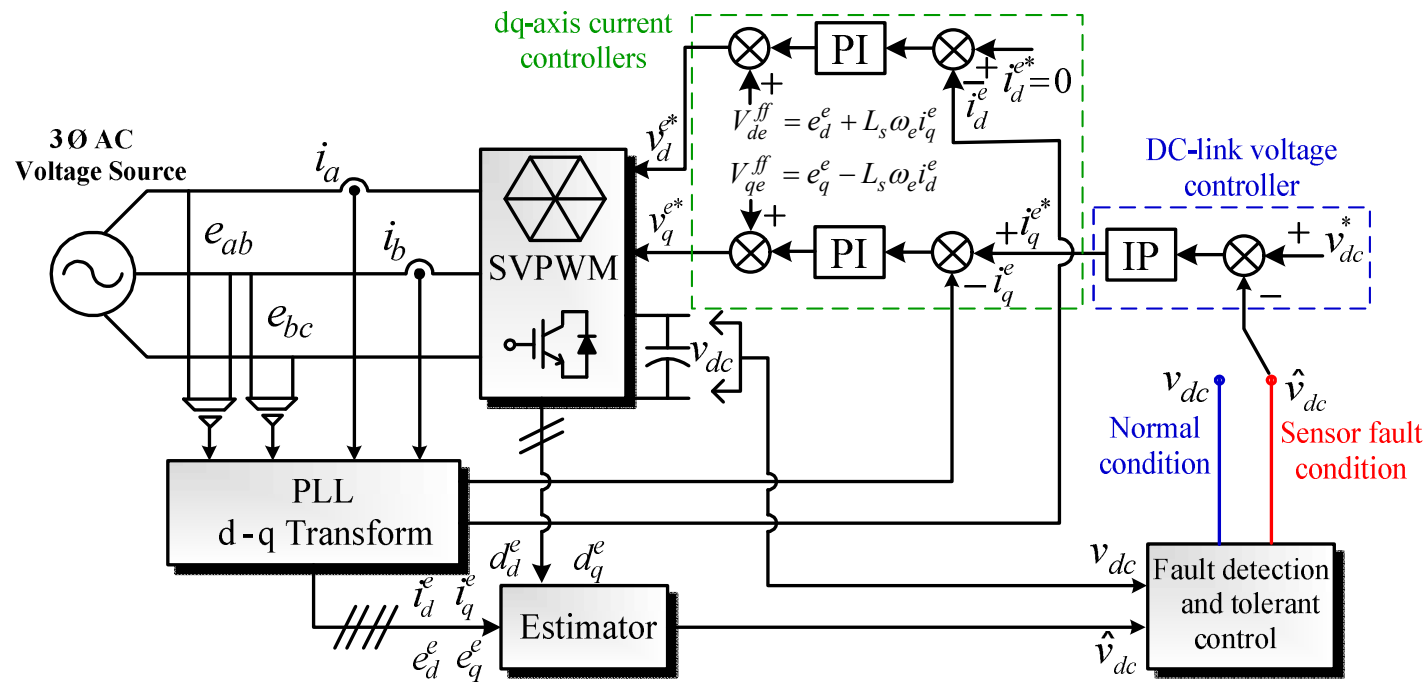

Fig. 3. Control block diagram of the AC/DC PWM converter.

To determine the eigenvalues of matrix (A-LC), the characteristic is expressed as:

$$
\operatorname{det}\left(\lambda_{L O} I-(A-L C)\right)=0
$$

where $\lambda_{L O}$ is the observer pole matrix as:

$$
\lambda_{L O}=\left[\begin{array}{lll}
\lambda_{1} & 0 & 0 \\
0 & \lambda_{2} & 0 \\
0 & 0 & \lambda_{3}
\end{array}\right], \quad I=\left[\begin{array}{lll}
1 & 0 & 0 \\
0 & 1 & 0 \\
0 & 0 & 1
\end{array}\right] .
$$

In this study, the observer pole locations are selected by trial and error as $-15,000$ and $-5,000 \pm j 3,000$. Then, from (17) and (19)-(21), the gain matrix $\mathbf{L}$ is calculated as:

$$
\mathbf{L}=\left[\begin{array}{ll}
L_{11} & L_{12} \\
L_{21} & L_{22} \\
L_{31} & L_{32}
\end{array}\right]=\left[\begin{array}{cc}
14,500 & 400 \\
-500 & 9,970 \\
-430 & -213,790
\end{array}\right] .
$$

\section{FAult Detection OF THE DC-LinK VoltaGE SENSOR AND TOLERANT CONTROL}

\section{A. Fault Detection of the DC-Link Voltage Sensor}

With the estimation of the DC-link voltage, the PWM converter can be controlled with a sensorless control algorithm, which reduces the whole system cost. Regardless of the cost reduction, the degree of redundancy for reliable operation of the system cannot be secured with only the sensorless control algorithm. For this degree of redundancy, the voltages and currents need to be both measured and estimated. Then, the converter can continue operating when a sensor fault occurs.

The sensor fails when it sends out a wrong signal with a significant error. The voltage is normally measured through hall sensors, analog scaling circuits consisting of an amplifier and a low-pass filter, and A/D (analog to digital) converters. Sensor failures sometimes occur due to a malfunction of the power supply of the sensors, and circuit board faults due to humidity, high temperature, etc [12], [14]. This study focuses on the fault detection of DC-link voltage sensors and tolerant control by a sensorless control algorithm when the failure of a sensor occurs.

The faults of DC-link voltage sensors are detected by a comparison of the measured DC-link voltage and the estimated one. If there is a significant difference between the two values, it is discerned that the sensor is faulty. When a sensor fault is detected, the fault flag, $F_{f}$, is set to 1 , while it is zero under normal conditions.

The voltage estimation error, $r(t)$, is calculated as:

$$
r(t)=\frac{\left|v_{d c}-\hat{v}_{d c}\right|}{v_{d c}^{*}} \cdot 100 \% .
$$

Then:

$$
\begin{array}{r}
\text { if } r(t)<V_{t h}, \text { then } F_{f}=0 \\
\text { or if } r(t) \geq V_{t h}, \text { then } F_{f}=1
\end{array}
$$

where $V_{t h}$ is a threshold value. In this study, $V_{t h}$ is chosen as $10 \%$.

\section{B. Control of AC/DC PWM Converters}

For three-phase AC/DC/AC PWM converters, the DC-link voltage is controlled by the source-side converter, where the control structure is cascaded by an outer voltage control loop and inner d-q current control loops as shown in Fig. 3 [1]. For DC-link voltage control without any overshoot in the transient states, an IP (integral-proportional) regulator is preferred, where the anti-windup technique is also employed [26], [27]. The $d q$-axis components of the source currents are regulated by PI (proportional-integral) controllers, where the crosscoupling terms and the source voltage as a disturbance are compensated in a feed-forward type, as shown in Fig. 3. 


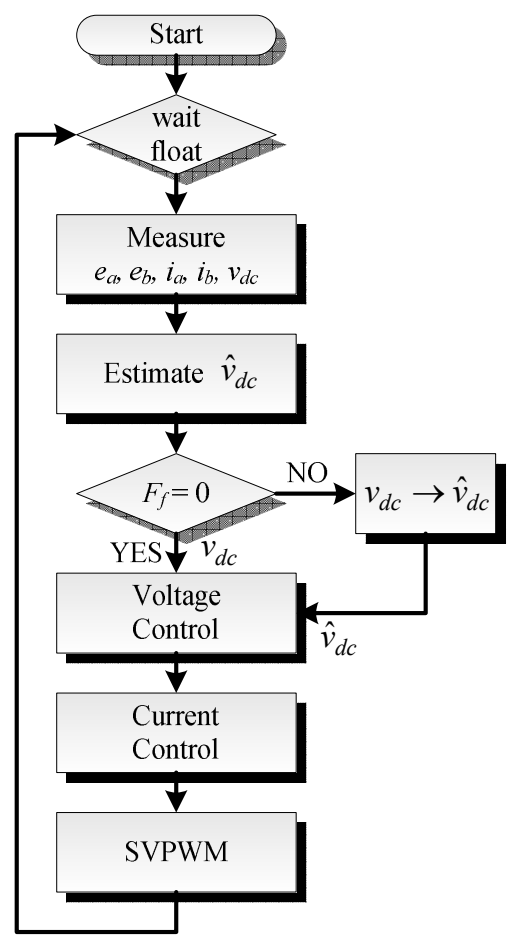

Fig. 4. Flow chart of fault tolerant control of voltage sensor.

TABLE I

PARAMETERS OF SOURCE-Side CONVERTER

\begin{tabular}{|c|c|}
\hline Source voltage & $220 \mathrm{~V} / 60 \mathrm{~Hz}$ \\
\hline Input resistor & $0.1 \Omega$ \\
\hline Boost inductor & $3.15 \mathrm{mH}$ \\
\hline DC-link capacitor & $1,650 \mu \mathrm{F}$ \\
\hline DC-link voltage & $360 \mathrm{~V}$ \\
\hline
\end{tabular}

When a sensor fault is detected, a fault tolerant control scheme is activated. In this case, the measured DC-link voltage is replaced by the estimated one for the feedback control, as shown in Fig. 3. Fig. 4 shows a flowchart of the sensor fault detection and tolerant control algorithm.

\section{SimULATION RESULtS}

Simulations using PSIM were carried out to verify the validity of the proposed method, where an induction machine drive is used as a load for the AC/DC/AC PWM converter. The system parameters for the source-side converter are listed in Table I. The switching frequency of the converters is $5 \mathrm{kHz}$. The sampling time is $100 \mu \mathrm{s}$. In the simulation, the controller gains were chosen so that the bandwidths of the current and voltage controllers are $398 \mathrm{~Hz}$ and $32 \mathrm{~Hz}$, respectively.

First, the estimation performance with the sliding mode observer [16], for the AC/DC/AC PWM converter under stepwise load variations was investigated, as shown in Fig. 5. The load profile applied to the AC/DC PWM converter is no load $\rightarrow 3 \mathrm{~kW} \rightarrow-2 \mathrm{~kW} \rightarrow$ no load. Fig. 5(a) shows the d-axis currents, where the estimated current converges to the actual (a)

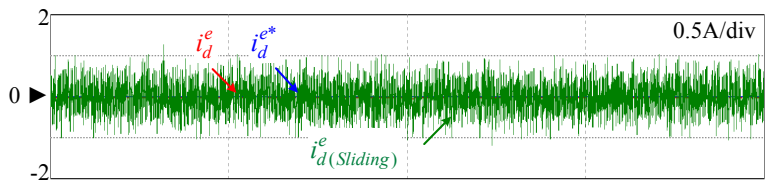

(b)

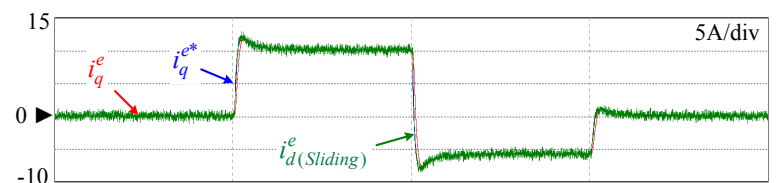

(c) 360

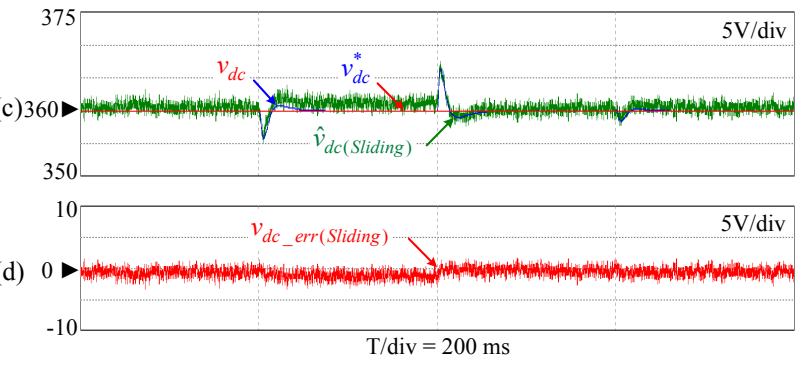

Fig. 5. Estimation performance using sliding mode observer in the case of abrupt load changes. (a) $d$-axis currents. (b) $q$-axis currents. (c) DC-link voltages. (d) DC-link voltage estimation error.

(a)

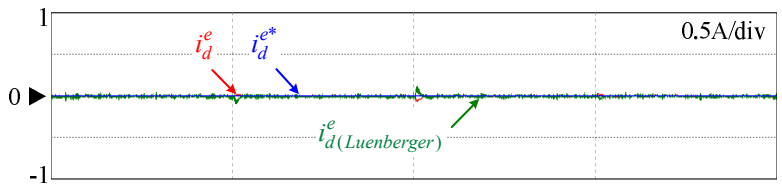

(b)

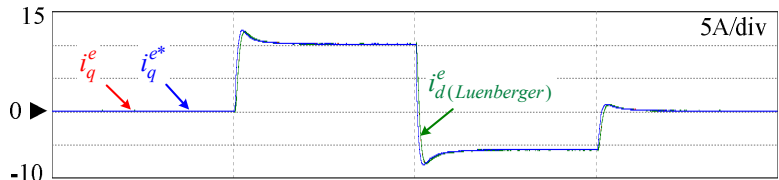

(c)

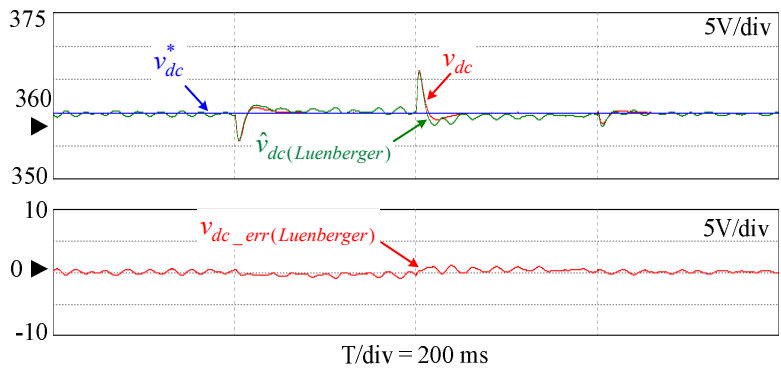

Fig. 6. Estimation performance of Luenberger observer in the case of abrupt load changes. (a) $d$-axis currents. (b) $q$-axis currents. (c) DC-link voltages. (d) DC-link voltage estimation error.

one. However, the ripple component of the estimated current is high. The same phenomena for the q-axis current and the DC-link voltage are shown in Fig. 5(b) and (c), respectively. Fig. 5(d) shows the estimation error of the DC-link voltage, which is about $3 \mathrm{~V}$.

Next, the performance of the Luenberger observer, under the same conditions as those used in the case of Fig. 5, is illustrated in Fig. 6, where the observer gains designed in section III are used. Fig. 6(a) shows the $d$-axis current, where the estimated current is nearly the same as the measured one. In addition, the 
(a)

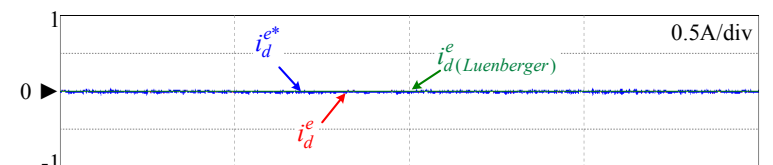

(b)

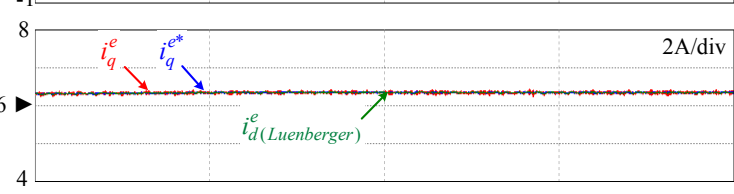

(c)

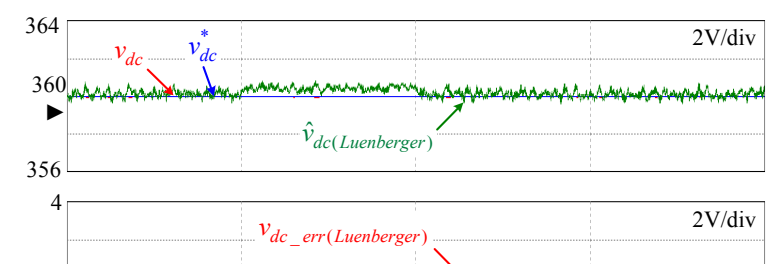

(d)
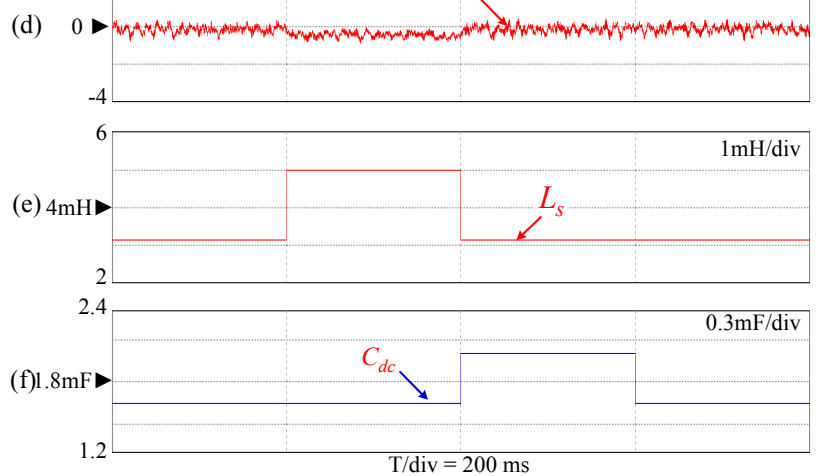

Fig. 7. Estimation performance of Luenberger observer in the case of parameter variations. (a) $d$-axis currents. (b) $q$-axis currents. (c) DC-link voltages. (d) DC-link voltage estimation error. (e) Variation of input filter inductance and DC-link capacitance.

$q$-axis current is estimated well, even under transient conditions, as shown in Fig. 6(b). Fig. 6(c) shows the estimated and measured DC-link voltages, which are very close. The estimation error is about $1.5 \mathrm{~V}$, which is shown in Fig. 6(d). These results show that the estimation performance is excellent even when the load is changed.

Fig. 7 shows the estimation performance of the Luenberger observer under parameter variations, where the parameter values are assumed to be changed in the controller rather than in the actual system. An increase of $40 \%$ in the input inductance or an increase of $20 \%$ in the DC-link capacitance have been considered, and are shown in Fig. 7(e) and (f), respectively. Fig. 7 (a) and (b) show the $d$ - and $q$-axis components of the source currents, respectively. It can be seen that the estimated currents follow the measured currents well. The measured and estimated DC-link voltages are shown in Fig. 7(c), and the estimation error is shown in Fig. 7(d). These results illustrate that the estimation error is less than $2 \mathrm{~V}$ even under parameter variations.

The control performance of the converter without the DC-link voltage sensor is shown in Fig. 8, were the estimated value of the DC-link voltage is used as the feedback control. The $d$ - and $q$-axis source currents follow their references well, and are (a)

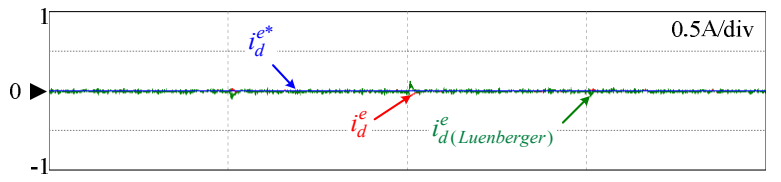

(b)

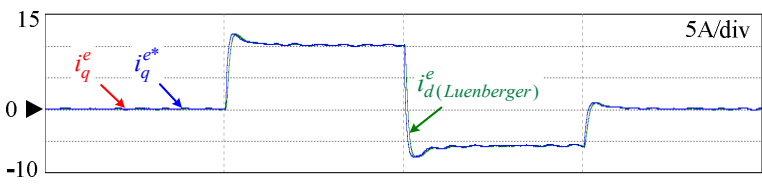

(c)

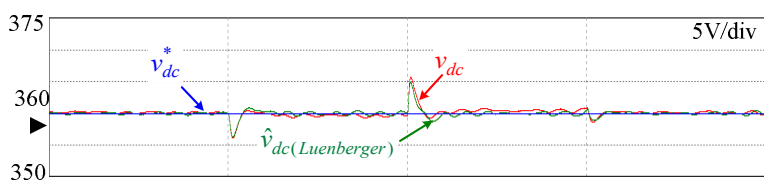

(d)

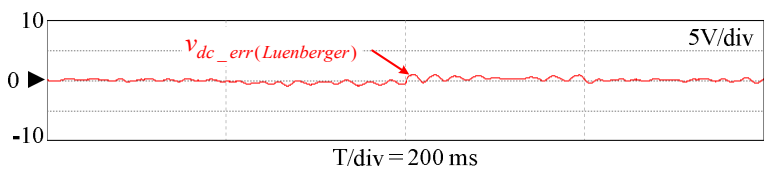

Fig. 8. Performance of DC-link voltage control without DC-link voltage sensor in the case of abrupt load changes. (a) $d$-axis currents. (b) $q$-axis currents. (c) DC-link voltages. (d) DC-link voltage estimation error.

(a)

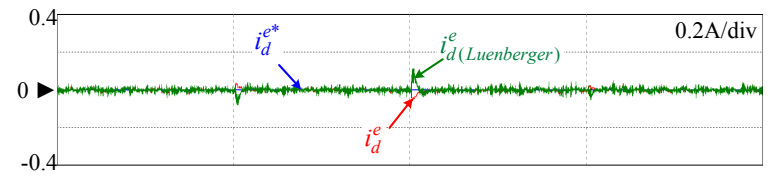

(b)

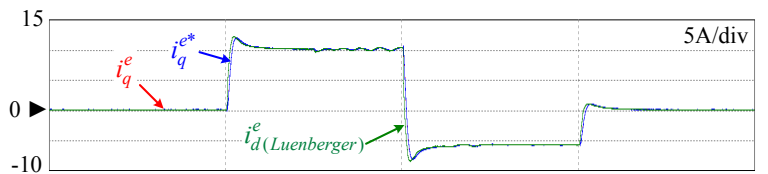

(c)

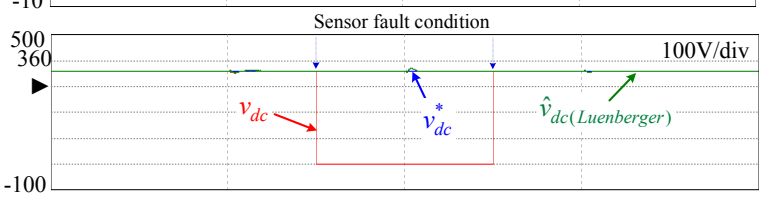

(d)

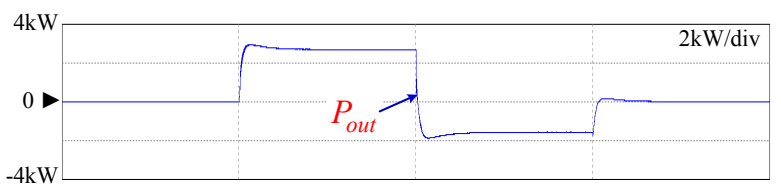

(e)

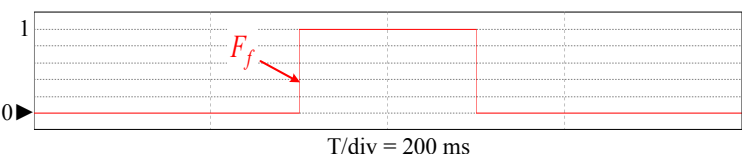

Fig. 9. Control performance of the fault tolerant control under the sensor failure of the DC-link voltage. (a) $d$-axis currents. (b) $q$ axis currents. (c) DC-link voltages. (d) Output power. (e) Fault flag.

shown in Fig. 8(a) and (b), respectively. Fig. 8(c) shows the DC-link voltage, which is well kept at its reference of $360 \mathrm{~V}$. The estimation error is shown in Fig. 8(d), where the maximum error in the transient state is less than $1.5 \mathrm{~V}$.

Fig. 9 shows the performance of the fault tolerant control under load variations when a fault of the DC-link voltage sensor 


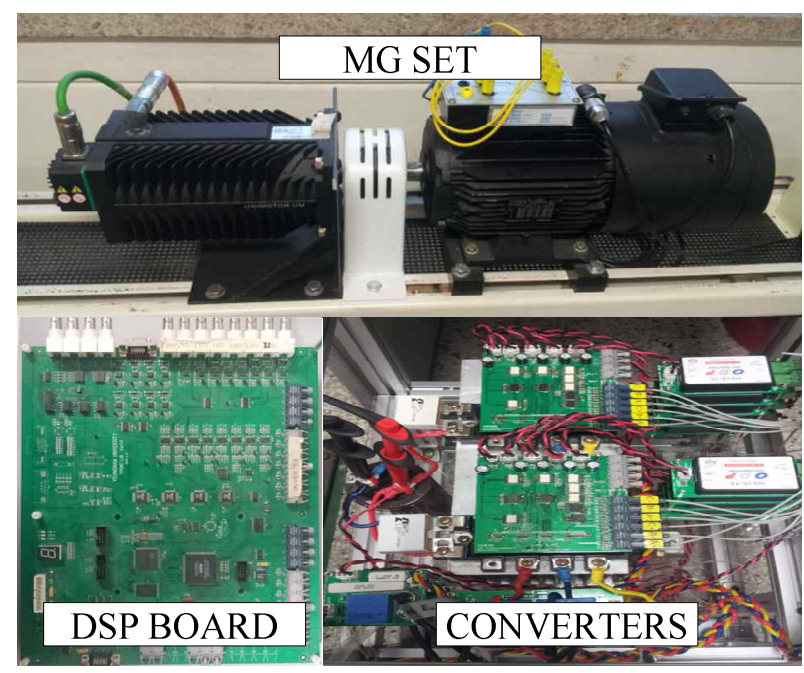

Fig. 10. Experimental setup.

occurs. For this investigation, it is assumed that the sensor fault occurs for an interval of $200 \mathrm{~ms}$, which is shown in Fig. 9(e). It can be seen in Fig. 9(c) that the sensed DC-link voltage is reduced to zero at the fault. However, with the fault tolerant control, the DC-link voltage is controlled well at its reference, as shown in Fig. 9(c). Fig. 9(a) and (b) show the $d$ - and $q$-axis current components, where the control performances are good even under sensor fault and load variation conditions. Fig. 9(d) shows the output power of the converter.

\section{EXPERIMENTAL RESULTS}

To verify the feasibility of the proposed method in practical applications, experimental tests were carried out in the laboratory for a three-phase AC/DC/AC PWM converter, which feeds an induction motor drive.

Fig. 10 shows the layout of the experimental setup. The parameters of the source-side converter are the same as those of the simulation as shown in Table 1. A DSP chip (TMS320VC33) is used as the main processor, and the switching frequency of the converters is $5 \mathrm{kHz}$. The experimental conditions are the same as those of the simulation.

Fig. 11 shows the estimation performance of the Luenberger observer when changing the converter parameters in the controller. Fig. 11(a) and (b) show an increase of $40 \%$ in both the input inductance and the DC-link capacitance. It can be seen in Fig. 11(c) that the DC-link voltage is estimated well, since the estimation error is about $7 \mathrm{~V}$ even in the case of parameter variations. Fig. 11(d) and (e) show the estimated and measured values of the $d$ - and $q$-axis components of the source currents, respectively.

Fig. 12 shows the control performance of the fault tolerant control for the PWM converter under a sensor failure of the DC-link voltage. The fault flag shown in Fig. 12(a) illustrates that the DC-link voltage sensor fault occurred at $4 \mathrm{~s}$, while the sensed DC-link voltage is zero during the fault, as shown in Fig.

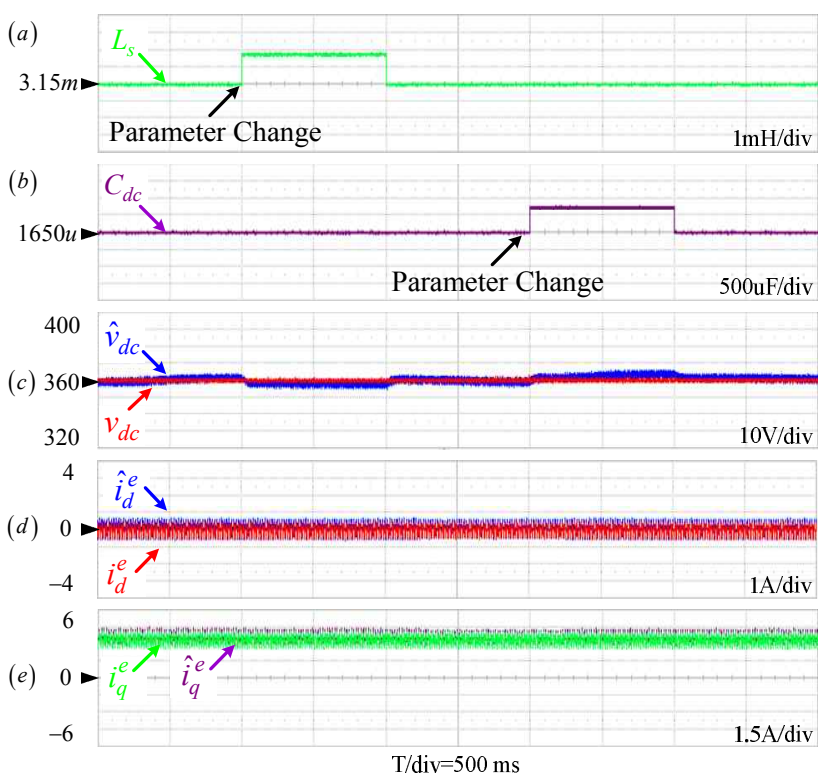

Fig. 11. Estimation performance of Luenberger observer in the case of parameter variations. (a) Variation of input filter inductance. (b) Variation of DC-link capacitance. (c) DC-link voltages. (d) $d$-axis currents. (e) $q$-axis currents.

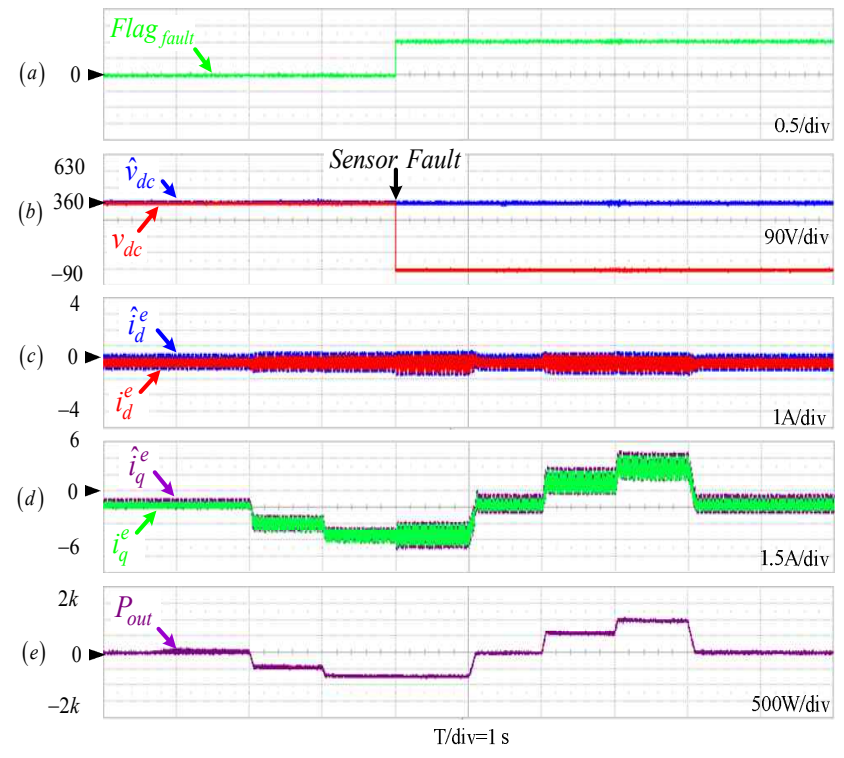

Fig. 12. Control performance of the fault tolerant control under the sensor failure of the DC-link voltage (exp.). (a) Fault flag. (b) DC-link voltages. (c) $d$-axis currents. (d) $q$-axis currents. (e) Output power.

12(b). However, the DC-link voltage is well kept at its reference of $360 \mathrm{~V}$ with the fault tolerant control. Fig. 12(c) and (d) show the $d$ - and $q$-axis current components, where the control performances are good even under sensor fault and load variation conditions. Fig. 12(e) shows the output power of the converter. 


\section{CONCLUSIONS}

In this paper, a fault detection and tolerant control scheme for the DC-link voltage sensors in three-phase $\mathrm{AC} / \mathrm{DC} / \mathrm{AC}$ PWM converters has been proposed, where the Luenberger observer is used to estimate the DC-link voltage. The linear Luenberger observer system has been built from a nonlinear model of the PWM converter, where the estimation error is about $1.5 \mathrm{~V}$ in the transient condition. With the proposed algorithm, the system reliability is improved, which can avoid tripping the system when sensor faults occur. The effectiveness of the proposed method has been verified by simulation and experimental results. They show that the estimation scheme works well under variations of the parameters in the PWM converter such as the input inductance and the DC-link capacitance.

\section{ACKNOWLEDGEMENT}

This work has been supported by KESRI (Korea Electrical Engineering and Science Research Institute) (2009T100100651), which was funded by MKE (Ministry of Knowledge Economy).

\section{REFERENCES}

[1] S.-K. Sul, Control of Electric Machine Drive Systems, Wiley-IEEE Press, 2010.

[2] Q. N. Trinh, H. H. Lee, and T. W. Chun, "An enhanced harmonic voltage compensator for general loads in standalone distributed generation systems," Journal of Power Electronics, Vol. 13, No. 6, pp. 1070-1079, Nov. 2013.

[3] T. H. Nguyen and D. C. Lee, "Control strategy for threephase grid-connected converters under unbalanced and distorted grid voltages using composite observers," Journal of Power Electronics, Vol. 13, No. 3, pp. 469-478, May 2013.

[4] S. Yang, D. Xiang, A. Bryant, P. Mawby, L. Ran, and P. Tavner, "Condition monitoring for device reliability in power electronic converters: a review," IEEE Trans. Power Electron., Vol. 25, No. 11, pp. 2734-2752, Nov. 2010.

[5] M. Boetthias and F. W. Fuchs, "Power electronic converters in wind energy systems - Considerations of reliability and strategies for increasing availability," in Proc. EPE, pp. 1-10, 2011.

[6] A. L. Julian and G. Oriti, "A comparison of redundant inverter topologies to improve voltage source inverter reliability," IEEE Trans. Ind. Appl., Vol. 43, No. 5, pp. 1371-1378, Sep./Oct. 2007.

[7] R. L. de A. Ribeiro, C. B. Jacobina, E. R. C. da Silva, and A. M. N. Lima, "Fault detection of open-switch damage in voltage-fed PWM motor drive system," IEEE Trans. Power Electron., Vol. 18, No. 2, pp. 587-593, Mar. 2003.

[8] Z. Gao and S. X. Ding, "Sensor fault reconstruction and sensor compensation for a class of nonlinear state-space systems via a descriptor system approach," IET Control Theory \& Applications, Vol. 1, No. 3, pp 578-585, May 2007.

[9] D.-E. Kim and D.-C. Lee, "Fault diagnosis of three-phase PWM inverters using wavelet and SVM," Journal of Power Electronics, Vol. 9, No. 3, pp. 377-385, May 2009.

[10] K.-W. Lee, M. Kim, J. Yoon, S.-B. Lee, and J.-Y. Yoo,
"Condition monitoring of DC-link electrolytic capacitors in adjustable-speed drives," IEEE Trans. Ind. Appl., Vol. 44, No. 5, pp.1606-1613. Sep./Oct. 2008.

[11] B. Lu and S. K. Sharma, "A literature review of IGBT fault diagnostic and protection methods for power inverters," IEEE Trans. Ind. Appl., Vol. 45, No. 5, pp. 1770-1777, Sep./Oct. 2009.

[12] T. A. Najafabadi, F. R. Salmasi, and P. J. Maralani, "Detection and isolation of speed-, DC-link voltage-, and current-sensor faults based on an adaptive observer in induction-motor drives," IEEE Trans. Ind. Electron., Vol. 58, No. 5, pp. 1662-1672, May 2011.

[13] Z. Wang, L. Chang, and M. Mao, "DC voltage sensorless control method for three-phase grid-connected inverters," IET Power Electron., Vol. 3, No. 4, pp. 552-558, Jul. 2010.

[14] Z. Wang and L. Chang, "A DC voltage monitoring and control method for three-phase grid-connected wind turbine inverters," IEEE Trans. Power Electron., Vol. 23, No. 3, pp. 1118-1125, May 2008.

[15] T. Ohnuki, O. Miyashita, P. Lataire and G. Maggetto, "Control of three-phase PWM rectifier using estimated AC-side and DC-side voltages." IEEE Trans. Power Electron., Vol. 14, No. 2, pp. 222-226, Mar. 1999.

[16] A. Sarinana, "A novel sliding mode observer applied to the three-phase voltage source inverter," in Proc. EPE, pp. 112, 2005.

[17] S. Fukuda, Y. Iwaji, and T. Aoyama, "Modeling and control of sinusoidal PWM rectifiers," in Proc. PEA, Vol. 4, pp.115-120, Sep. 1993.

[18] H. Mao and F. C. Y. Lee, "Novel reduced-order smallsignal model of three-phase PWM rectifiers and its application in control design and system analysis," IEEE Trans. Power Electron., Vol. 13, No. 3, pp. 511-521, May 1998.

[19] N. Hur, J. Jung, and K. Nam "A fast dynamic DC-link power-balancing scheme for a PWM converter-inverter system," IEEE Trans. Ind. Electron., Vol. 48, No. 4, pp.794-803. Aug. 2001.

[20] H.-S. Song, I.-W. Joo, and K.-H. Nam "Source voltage sensorless estimation scheme for PWM rectifiers under unbalanced conditions," IEEE Trans. Ind. Electron., Vol. 50, No. 6, pp. 1238-1245, Dec. 2003.

[21] K. Lee, V. Blasko, T. M. Jahns, and T. A. Lipo, "Input harmonic estimation and control methods in active rectifiers," in Proc. PESE, pp. 4517-4523, 2008.

[22] K. Lee, T. M. Jahns, T. A. Lipo, and V. Blasko "New observer-based source voltage unbalance control methods in PWM voltage-source converters," in Proc. PESC 2008, pp. 1509-1514, Jun. 2008.

[23] K. Lee, T. M. Jahns, T. A. Lipo, and V. Blasko "New control method including state observer of voltage unbalance for grid voltage-source converters," IEEE Trans. Ind. Electron., Vol. 57, No. 6, pp. 2054-2065, Jun. 2010.

[24] E.-S. Jung and S.-K. Sul "Control scheme for source voltage sensorless PWM converters under source voltage unbalance," in Proc. EPE 2011, pp. 1-10, Sep. 2011.

[25] F. Golnaraghi and B. C. Kuo, Automatic control systems, Wiley Book, $9^{\text {th }}$ edition, 2009.

[26] D.-C. Lee and G.-M. Lee "Anti-windup of current regulators considering inverter saturation," in Proc. EPE'97 Conf., pp. 3836-3841, 1997.

[27] D.-C. Lee and D.-S. Lim, "AC voltage and current sensorless control of three-phase PWM rectifiers," IEEE Trans. Power Electron., Vol. 17, No. 6, pp. 883-890, Nov. 2002. 


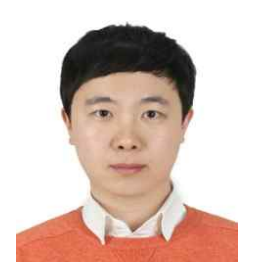

Soo-Cheol Kim was born in 1985 . He received his B.S. and M.S. degrees in Electrical Engineering from Yeungnam University, Gyeongsan, Korea, in 2011 and 2013, respectively. He is presently with Daewoo Shipbuilding and Marine Engineering Co., Ltd., Seoul, Korea. His current research interests include AC machine drives, the control of power converters, and electric propulsion systems.

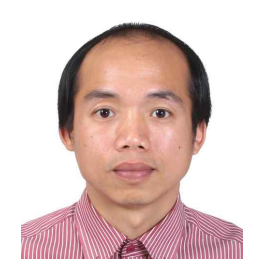

Thanh Hai Nguyen was born in Dong Thap, Vietnam. He received his B.S. degree in Engineering from the Ho Chi Minh City University of Technology, Ho Chi Minh City, Vietnam, in 2003, and his M.S. and Ph.D. degrees in Electrical Engineering from Yeungnam University, Gyeongbuk, Korea, in 2010 and 2013, respectively. He is presently working as a Research Professor at Yeungnam University. He was an Assistant Lecturer in the College of Technology, Can Tho University, Can Tho, Vietnam, from May 2003 to February 2008. His current research interests include power converters, machine drives, HVDC transmission systems, and wind power generation.

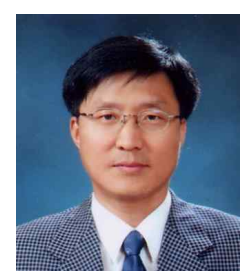

Dong-Choon Lee received his B.S., M.S., and Ph.D. degrees in Electrical Engineering from Seoul National University, Seoul, Korea, in 1985, 1987, and 1993, respectively. He was a Research Engineer with Daewoo Heavy Industry, Korea, from 1987 to 1988. Since 1994, he has been a faculty member in the Department of Electrical Engineering, Yeungnam University, Gyeongbuk, Korea. As a Visiting Scholar, he joined the Power Quality Laboratory, Texas A\&M University, College Station, TX, USA, in 1998, the Electrical Drive Center, University of Nottingham, Nottingham, U.K., in 2001, the Wisconsin Electric Machines and Power Electronic Consortium, University of Wisconsin, Madison, Wisconsin, USA, in 2004, and the FREEDM Systems Center, North Carolina State University, Raleigh, North Carolina, USA, from September 2011 to August 2012. His current research interests include ac machine drives, the control of power converters, wind power generation, and power quality. Professor Lee is currently a Publication Editor for the Journal of Power Electronics of the Korean Institute of Power Electronics.

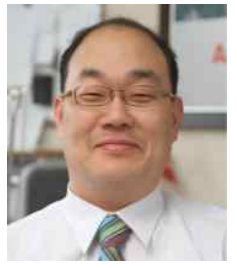

Kyo-Beum Lee received the B.S. and M.S. degrees in electrical and electronic engineering from the Ajou University, Korea, in 1997 and 1999, respectively. He received the $\mathrm{Ph} . \mathrm{D}$. degree in electrical engineering from the Korea University, Korea in 2003. From 2003 to 2006, he was with the Institute of Energy Technology, Aalborg University, Aalborg, Denmark. From 2006 to 2007, he was with the Division of Electronics and Information Engineering, Chonbuk National University, Jeonju, Korea. In 2007 he joined the School of Electrical and Computer Engineering, Ajou University, Suwon, Korea. He is an associated editor of the IEEE Transactions on Power Electronics and the Journal of Power Electronics. His research interests include electric machine drives, electric vehicles, and renewable power generations.

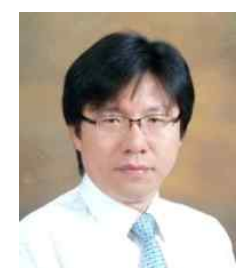

Jang-Mok Kim was born in Busan, Korea, in August 1961. He received his B.S. degree from Pusan National University (PNU), Pusan, Korea, in 1988, and his M.S. and Ph.D. degrees from the Department of Electrical Engineering, Seoul National University, Seoul, Korea, in 1991 and 1996, respectively. From 1997 to 2000, he was a Senior Research Engineer with the Korea Electrical Power Research Institute (KEPRI). Since 2001, he has been with the School of Electrical Engineering, Pusan National University (PNU), where he is presently a Faculty Member. In addition, he is a Research Member of the Research Institute of Computer Information and Communication at PNU. His current research interests include the control of electric machines, electric vehicle propulsion, and power quality. 